\title{
Relation Between High-Sensitivity C-Reactive Protein and Coronary Plaque Components in Patients With Acute Coronary Syndrome: Virtual Histology-Intravascular Ultrasound Analysis
}

\author{
Young Joon Hong, MD, Myung Ho Jeong, MD, Yun Ha Choi, RN, Suk Hee Cho, PhD, Seung Hwan Hwang, MD, \\ Jum Suk Ko, MD, Min Goo Lee, MD, Keun Ho Park, MD, Doo Sun Sim, MD, Nam Sik Yoon, MD, \\ Hyun Ju Yoon, MD, Kye Hun Kim, MD, Hyung Wook Park, MD, Ju Han Kim, MD, \\ Youngkeun Ahn, MD, Jeong Gwan Cho, MD, Jong Chun Park, MD, and Jung Chaee Kang MD \\ Heart Center of Chonnam National University Hospital, Chonnam National University Research Institute of Medical Sciences, \\ Gwangju, Korea
}

\begin{abstract}
Background and Objectives: We used virtual histology-intravascular ultrasound (VH-IVUS) to evaluate the relationship between high-sensitivity C-reactive protein (hs-CRP) levels and plaque components in 279 acute coronary syndrome (ACS) patients. Subjects and Methods: We divided patients into three groups according to their hs-CRP levels \{lowest tertile $<0.07$ $\mathrm{mg} / \mathrm{dL}$ ( $\mathrm{n}=93$ ), middle tertile $\geq 0.07,<0.4 \mathrm{mg} / \mathrm{dL}$ ( $\mathrm{n}=93$ ), and highest tertile $\geq 0.4 \mathrm{mg} / \mathrm{dL}$ ( $\mathrm{n}=93$ ) $\}$. Thin-cap fibroatheroma (TCFA) was defined as focal, necrotic core (NC)-rich ( $\geq 10 \%$ of the cross-sectional area) plaques in contact with the lumen in a plaque burden $\geq 40 \%$. Results: The highest tertile group was mostly diabetics $(20 \%, 27 \%, 40 \%, p=0.009)$, and had the greatest plaque plus media volume $\left(163 \pm 139 / \mathrm{mm}^{3}\right.$ vs. $201 \pm 155 / \mathrm{mm}^{3}$ vs. $\left.232 \pm 176 / \mathrm{mm}^{3}, \mathrm{p}=0.013\right)$. The highest tertile group had the greatest absolute and \% NC volumes $\left(13.6 \pm 15.1 \mathrm{~mm}^{3}\right.$ vs. $14.8 \pm 14.2 \mathrm{~mm}^{3}$ vs. $23.7 \pm 24.3 \mathrm{~mm}^{3}, \mathrm{p}<0.001$, and $14.9 \pm 8.7 \%$ vs. $16.0 \pm 8.7 \%$ vs. $19.5 \pm 10.2 \%, \mathrm{p}=0.024$, respectively). The culprit lesion TCFA was observed most frequently in the highest tertile group ( $28 \%$ vs. $35 \%$ vs. $55 \%$, $\mathrm{p}=0.006$ ). By multivariable analysis, absolute NC volume was an independent predictor of hsCRP elevation \{odds ratio (OR); 1.03, 95\% confidence interval $(\mathrm{CI})=1.06-1.21, \mathrm{p}=0.004\}$, and hs-CRP was an independent predictor of TCFA (OR; 1.86, 95\% CI=1.11-2.90, $\mathrm{p}=0.010$ ). Conclusion: VH-IVUS analysis has demonstrated that ACS patients with elevated hs-CRP have more vulnerable plaque component (NC-rich plaques and higher frequency of culprit lesion TCFA), compared with ACS patients with normal hs-CRP. (Korean Circ J 2011;41:440-446)
\end{abstract}

KEY WORDS: Acute coronary syndrome; Plaque, atherosclerotic; Inflammation; Ultrasonography, interventional.

\section{Introduction}

Vascular inflammation plays a pivotal role in atherogenesis and thrombotic events. ${ }^{1)}$ High-sensitivity C-reactive protein

Received: July 15, 2010

Accepted: September 1, 2010

Correspondence: Myung Ho Jeong, MD, Heart Research Center of Chonnam National University Hospital, Chonnam National University Research Institute of Medical Sciences, 671 Jaebong-ro, Dong-gu, Gwangju 501-757, Korea

Tel: 82-62-220-6243, Fax: 82-62-228-7174

E-mail: myungho@chollian.net

- The authors have no financial conflicts of interest.

$\circledast$ This is an Open Access article distributed under the terms of the Creative Commons Attribution Non-Commercial License (http://creativecommons.org/licenses/by-nc/3.0) which permits unrestricted non-commercial use, distribution, and reproduction in any medium, provided the original work is properly cited.
(hs-CRP) has been associated with metabolic syndrome ${ }^{2)}$ and with elevated risks for the development of coronary artery disease. ${ }^{3)}$ hs-CRP has emerged as a simple tool for detecting systemic inflammation in patients with subsequent coronary events. ${ }^{4)}$ Measurement of hs-CRP has been recommended for patients to refine risk assessment. ${ }^{5}$

Several grey-scale intravascular ultrasound (IVUS) studies have demonstrated increased incidence of culprit-lesion plaque rupture in patients with acute coronary syndrome (ACS) ${ }^{6-8)}$ There is a strong inflammatory response to tissue injury that occurs during ACS, and plaque rupture and the extent of inflammatory response may be an important determinant of clinical outcome. ${ }^{9)}$ Several studies have reported that CRP elevation was associated with culprit lesion plaque rupture in ACS patients. ${ }^{67) 10)}$ Recently, several virtual histology (VH)- 
IVUS studies have demonstrated coronary plaque components in ACS patients. ${ }^{11) 12}$

In spite of the strong association between CRP levels and vulnerable plaque using grey-scale IVUS, no studies have demonstrated a relationship between inflammatory response indicated by CRP, and plaque characteristics in ACS patients. Therefore, the aim of this study was to assess the relationship between hs-CRP levels and plaque characteristics, including plaque composition, and the incidence of thin-cap fibroatheroma (TCFA) in ACS patients.

\section{Subjects and Methods}

\section{Patient population}

This study was a retrospective, single-center study. From July 2007 to June 2008, 279 consecutive ACS patients who underwent VH-IVUS for native, de novo coronary lesions and underwent pre-procedural hs-CRP evaluation were included in this study. We divided patients into three groups according to their pre-procedural hs-CRP levels \{lowest tertile $<0.07 \mathrm{mg} / \mathrm{dL}$ ( $\mathrm{n}=93$ ), middle tertile $\geq 0.07,<0.4 \mathrm{mg} / \mathrm{dL}$ ( $\mathrm{n}=$ 93 ), and highest tertile $>0.4 \mathrm{mg} / \mathrm{dL}(\mathrm{n}=93)\}$. The presence of unstable angina was determined by chest pain within the preceding 72 hours with or without ST-T-wave changes, or positive cardiac biochemical markers (creatine kinase-myocardial band or cardiac specific troponin-I). The presence of ST-segment elevation myocardial infarction was determined by $>30$ minutes of continuous chest pain, new ST-segment elevation $\geq 2 \mathrm{~mm}$ on at least 2 contiguous electrocardiographic leads, and creatine kinase-MB (CK-MB) $>3$ times the normal limit. The presence of non-ST-segment elevation myocardial infarction was diagnosed by chest pain, and positive cardiac biochemical markers (creatine kinase-myocardial band or cardiac specific troponin-I) without new ST-segment elevation. The protocol was approved by the institutional review board. Hospital records of patients were reviewed to obtain information on clinical demographics.

\section{Laboratory analysis}

Venous blood samples were obtained before the IVUS study within 24 hours of symptom onset. Blood samples were centrifuged, and serum was removed and stored at $-70^{\circ} \mathrm{C}$ until the assay could be performed. hs-CRP was assessed by the immunoturbidimetric CRP-Latex (II) hs assay using an Olympus 5431 autoanalyzer. The assay was performed according to the manufacturer's protocol, and has been validated against the Dade-Behring method. ${ }^{13)}$ This assay has a coefficient of variation of 5\%. Serum N-terminal pro-B-type natriuretic peptide was measured using an electrochemiluminescence sandwich immunoassay method with an Elecsys 2010 analyzer (Roche Diagnostics, Mannheim, Germany). Absolute CK-MB levels were determined by radioimmuno- assay (Dade Behring Inc., Miami, FL, USA). Cardiac-specific troponin I levels were measured by paramagnetic particle, chemiluminescent immunoenzymatic assay (Beckman, Coulter Inc., Fullerton, CA, USA). The serum levels of total cholesterol, triglyceride, low-density lipoprotein-cholesterol (LDLC), and high-density lipoprotein cholesterol were measured by standard enzymatic methods.

\section{Angiographic analysis}

Coronary angiogram was analyzed with a validated quantitative coronary angiography (QCA) system (Phillips H5000 or Allura DCI program, Philips Medical Systems, Eindhoven, the Netherlands). The outer diameter of the contrastfilled catheter was the calibration standard. Minimal lumen and reference diameters were measured in diastolic frames from orthogonal projections.

\section{Intravascular ultrasound imaging and analysis}

All pre-intervention grey-scale and VH-IVUS examinations were performed after intracoronary administration of $300 \mu \mathrm{g}$ nitroglycerin. A 20-MHz, 2.9F IVUS imaging catheter (Eagle Eye, Volcano Corp, Rancho Cordova, CA, USA) was advanced $>10 \mathrm{~mm}$ beyond the lesion. Automated pullback was performed to a point $>10 \mathrm{~mm}$ proximal to the lesion at a speed of $0.5 \mathrm{~mm} / \mathrm{sec}$.

Quantitative volumetric grey-scale and VH-IVUS analyses were performed across the entire lesion segment, and crosssectional analysis was performed at the minimum lumen sites. Conventional quantitative volumetric grey-scale IVUS analysis was performed according to the American College of Cardiology Clinical Expert Consensus Document on Standards for Acquisition, Measurement and Reporting of Intravascular Ultrasound Studies. ${ }^{14)}$ External elastic membrane (EEM) and lumen cross-sectional areas (CSAs) were measured. Plaque plus media (P\&M) CSA was calculated as EEM minus lumen CSA. Plaque burden was calculated as P\&M divided by EEM CSA. Proximal and distal references were the single slices with the largest lumen and smallest plaque burden within $10 \mathrm{~mm}$ proximally and distally, but before any large side branch. VH-IVUS analysis classified color-coded tissue into four major components: green (fibrotic); yellow-green (fibro-fatty); white (dense calcium); and red (necrotic core, NC) (Fig. 1). ${ }^{1115)}$ VH-IVUS analysis was reported in absolute quantity, and as a percentage of the plaque area or volume. TCFA was defined as NC $\geq 10 \%$ of plaque area in at least 3 consecutive frames without overlying fibrous tissue, in the presence of $\geq 40 \%$ plaque burden. ${ }^{11}$

\section{Statistical analysis}

The Statistical Package for the Social Sciences (SPSS) for Windows, version 15.0 (Chicago, IL, USA) was used for all analyses. Continuous variables were presented as mean $\pm \mathrm{SD}$; 

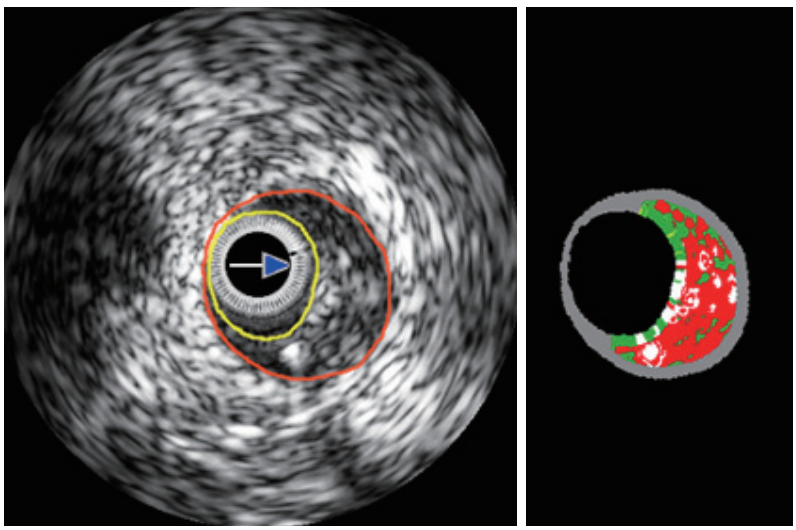

\section{Lumen Area}

Vessel Area

Plaque Area

$\%$ Plaque Burden

FI Green Area

FF Light Green Are

DC White Area

NC Red Area
$3.9 \mathrm{~mm}^{2}$

$10.4 \mathrm{~mm}^{2}$

$6.5 \mathrm{~mm}^{2}$

$62 \%$

$1.0 \mathrm{~mm}^{2}$

$0.0 \mathrm{~mm}^{2}$

$0.6 \mathrm{~mm}^{2}$ $2.3 \mathrm{~mm}^{2}$

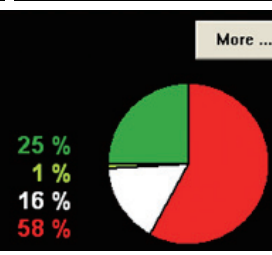

Fig. 1. The example of virtual histology-intravascular ultrasound image. comparisons were conducted by Student's t-test or the Wilcoxon rank-sum test if normality assumption was violated. Discrete variables were presented as percentages and frequencies. Comparisons were conducted by chi-square statistics or Fisher's exact test as appropriate. Multivariable analysis was performed to identify independent predictors of hsCRP elevation $(\geq 0.4 \mathrm{mg} / \mathrm{dL})$, and culprit lesion TCFA. A $\mathrm{p}<$ 0.05 was considered statistically significant.

\section{Results}

\section{Patient characteristics}

Patient baseline characteristics are summarized in Table 1. Mean hs-CRP levels were $0.04 \mathrm{mg} / \mathrm{dL}$ in lowest tertile group, $0.19 \mathrm{mg} / \mathrm{dL}$ in middle tertile group, and $1.85 \mathrm{mg} / \mathrm{dL}$ in highest tertile group. Ejection fraction was lowest, $\mathrm{N}$-terminal proB-type natriuretic peptide, white blood cell count, glucose, low-density lipoprotein cholesterol, and triglyceride levels were highest, hemoglobin level was lowest, and CK-MB and

Table 1. Baseline characteristics

\begin{tabular}{|c|c|c|c|c|}
\hline & Lowest tertile $(\mathrm{n}=93)$ & Middle tertile $(n=93)$ & Highest tertile $(n=93)$ & $\mathrm{p}$ \\
\hline hs-CRP (mg/dL) & $0.04 \pm 0.02$ & $0.19 \pm 0.09$ & $1.85 \pm 2.59$ & $<0.001$ \\
\hline Age (years) & $62 \pm 10$ & $60 \pm 12$ & $58 \pm 13$ & 0.060 \\
\hline Male gender (\%) & $61(66)$ & $69(74)$ & $64(69)$ & 0.4 \\
\hline Clinical presentation (\%) & & & & 0.7 \\
\hline Unstable angina & $45(48)$ & $40(43)$ & $37(40)$ & \\
\hline NSTEMI & $26(28)$ & $28(30)$ & $26(28)$ & \\
\hline STEMI & $22(24)$ & $25(27)$ & $30(32)$ & \\
\hline Diabetes mellitus (\%) & $19(20)$ & $25(27)$ & $37(40)$ & 0.003 \\
\hline Hypertension (\%) & $73(79)$ & $76(82)$ & $79(85)$ & 0.5 \\
\hline Smoking (\%) & $37(40)$ & $39(42)$ & $35(38)$ & 0.8 \\
\hline Family history of coronary artery disease (\%) & $5(5)$ & $3(3)$ & $2(2)$ & 0.5 \\
\hline Prior MI (\%) & $4(4)$ & $3(3)$ & $3(3)$ & 0.9 \\
\hline Ejection fraction (\%) & $64 \pm 7$ & $62 \pm 9$ & $59 \pm 9$ & $<0.001$ \\
\hline NT-pro-BNP (pg/mL) & $93 \pm 94$ & $229 \pm 264$ & $688 \pm 769$ & $<0.001$ \\
\hline White blood cell $\left(/ \mathrm{mm}^{3}\right)$ & $6324 \pm 1376$ & $9401 \pm 3399$ & $9491 \pm 2818$ & $<0.001$ \\
\hline Hemoglobin (g/dL) & $13.2 \pm 1.7$ & $12.8 \pm 1.3$ & $12.2 \pm 1.9$ & 0.001 \\
\hline Platelet count $\left(10^{3} / \mathrm{mm}^{3}\right)$ & $225 \pm 48$ & $234 \pm 57$ & $243 \pm 130$ & 0.4 \\
\hline Creatinine $(\mathrm{mg} / \mathrm{dL})$ & $0.84 \pm 0.18$ & $0.88 \pm 0.16$ & $0.87 \pm 0.26$ & 0.4 \\
\hline Glucose (mg/dL) & $138 \pm 53$ & $134 \pm 33$ & $154 \pm 54$ & 0.031 \\
\hline Creatine kinase-MB (U/L) & $4.9 \pm 1.9$ & $15.2 \pm 15.2$ & $27.6 \pm 17.6$ & 0.001 \\
\hline Troponin-I (ng/mL) & $0.05 \pm 0.14$ & $3.9 \pm 6.2$ & $10.8 \pm 10.6$ & 0.001 \\
\hline Total cholesterol (mg/dL) & $174 \pm 38$ & $186 \pm 51$ & $198 \pm 34$ & 0.001 \\
\hline Triglyceride (mg/dL) & $95 \pm 55$ & $126 \pm 89$ & $142 \pm 61$ & $<0.001$ \\
\hline $\mathrm{LDL}-\mathrm{C}(\mathrm{mg} / \mathrm{dL})$ & $113 \pm 35$ & $117 \pm 43$ & $132 \pm 28$ & 0.001 \\
\hline $\mathrm{HDL}-\mathrm{C}(\mathrm{mg} / \mathrm{dL})$ & $49 \pm 10$ & $49 \pm 13$ & $47 \pm 13$ & 0.6 \\
\hline
\end{tabular}

hs-CRP: high-sensitivity C-reactive protein, NSTEMI: non-ST segment elevation myocardial infarction, STEMI: ST segment elevation myocardial infarction, MI: myocardiol infraction, NT-pro-BNP: N-terminal pro-B-type natriuretic peptide, LDL-C: low density lipoprotein-cholesterol, HDL-C: high density lipoprotein-cholesterol 
Table 2. Coronary angiographic findings

\begin{tabular}{|c|c|c|c|c|}
\hline & Lowest tertile $(\mathrm{n}=93)$ & Middle tertile $(n=93)$ & Highest tertile $(n=93)$ & $\mathrm{p}$ \\
\hline Culprit lesion, n (\%) & & & & 0.5 \\
\hline Left anterior descending & $60(65)$ & $56(60)$ & $63(68)$ & \\
\hline Left circumflex & $14(15)$ & $20(22)$ & $11(12)$ & \\
\hline Right & $19(20)$ & $17(18)$ & $19(20)$ & \\
\hline Lesion location, $\mathrm{n}(\%)$ & & & & 0.9 \\
\hline Ostium & $5(5)$ & $4(4)$ & $3(3)$ & \\
\hline Proximal & $37(40)$ & $35(38)$ & $42(45)$ & \\
\hline Middle & $28(30)$ & $33(36)$ & $28(30)$ & \\
\hline Distal & $23(25)$ & $21(23)$ & $20(22)$ & \\
\hline Diseased vessel number, n (\%) & & & & 0.5 \\
\hline 1 & $56(60)$ & $51(55)$ & $47(51)$ & \\
\hline 2 & $23(25)$ & $26(28)$ & $23(25)$ & \\
\hline 3 & $14(15)$ & $16(17)$ & $23(25)$ & \\
\hline TIMI flow grade, $\mathrm{n}(\%)$ & & & & 0.3 \\
\hline 0 & $2(2)$ & $4(4)$ & $6(7)$ & \\
\hline 1 & $2(2)$ & $4(4)$ & $7(8)$ & \\
\hline 2 & $2(2)$ & $3(3)$ & $5(5)$ & \\
\hline 3 & $87(94)$ & $82(89)$ & $75(81)$ & \\
\hline Reference diameter (mm) & $3.17 \pm 0.57$ & $3.02 \pm 0.54$ & $3.32 \pm 0.56$ & 0.13 \\
\hline $\operatorname{MLD}(\mathrm{mm})$ & $1.67 \pm 0.63$ & $1.21 \pm 0.52$ & $1.06 \pm 0.61$ & $<0.001$ \\
\hline
\end{tabular}

TIMI: Thrombolysis in Myocardial Infarction, MLD: minimal lumen diameter

Table 3. Grey-scale intravascular ultrasound findings

\begin{tabular}{|c|c|c|c|c|}
\hline & Lowest tertile $(n=93)$ & Middle tertile $(n=93)$ & Highest tertile $(n=93)$ & $\mathrm{p}$ \\
\hline \multicolumn{5}{|l|}{ Proximal reference } \\
\hline $\operatorname{EEM} \mathrm{CSA}\left(\mathrm{mm}^{2}\right)$ & $19.9 \pm 6.8$ & $19.0 \pm 6.3$ & $21.2 \pm 6.8$ & 0.10 \\
\hline Lumen CSA $\left(\mathrm{mm}^{2}\right)$ & $12.4 \pm 8.0$ & $11.6 \pm 6.7$ & $13.1 \pm 8.5$ & 0.4 \\
\hline P\&M CSA $\left(\mathrm{mm}^{2}\right)$ & $7.5 \pm 3.5$ & $7.4 \pm 2.9$ & $8.1 \pm 3.7$ & 0.12 \\
\hline Plaque burden (\%) & $37 \pm 9$ & $38 \pm 8$ & $37 \pm 8$ & 0.6 \\
\hline \multicolumn{5}{|l|}{ Minimum lumen site } \\
\hline $\operatorname{EEM~CSA~}\left(\mathrm{mm}^{2}\right)$ & $16.5 \pm 6.5$ & $15.9 \pm 5.8$ & $17.8 \pm 7.2$ & 0.13 \\
\hline Lumen CSA $\left(\mathrm{mm}^{2}\right)$ & $7.2 \pm 4.5$ & $6.3 \pm 3.5$ & $6.9 \pm 3.5$ & 0.3 \\
\hline P\&M CSA $\left(\mathrm{mm}^{2}\right)$ & $9.3 \pm 3.4$ & $9.6 \pm 4.2$ & $11.0 \pm 5.1$ & 0.020 \\
\hline Plaque burden (\%) & $57 \pm 13$ & $60 \pm 13$ & $61 \pm 13$ & 0.18 \\
\hline IVUS lesion length $(\mathrm{mm})$ & $18 \pm 13$ & $21 \pm 12$ & $24 \pm 14$ & 0.016 \\
\hline \multicolumn{5}{|l|}{ Distal reference } \\
\hline $\operatorname{EEM~CSA~}\left(\mathrm{mm}^{2}\right)$ & $16.4 \pm 7.3$ & $15.2 \pm 6.5$ & $17.5 \pm 7.6$ & 0.11 \\
\hline Lumen CSA $\left(\mathrm{mm}^{2}\right)$ & $10.3 \pm 4.7$ & $9.3 \pm 4.1$ & $10.9 \pm 4.6$ & 0.075 \\
\hline P\&M CSA $\left(\mathrm{mm}^{2}\right)$ & $6.1 \pm 3.2$ & $5.8 \pm 2.7$ & $6.7 \pm 3.8$ & 0.2 \\
\hline Plaque burden (\%) & $37 \pm 8$ & $38 \pm 7$ & $37 \pm 8$ & 0.5 \\
\hline \multicolumn{5}{|l|}{ Volumetric analysis $\left(\mathrm{mm}^{3}\right)$} \\
\hline EEM volume & $332 \pm 245$ & $405 \pm 296$ & $544 \pm 361$ & 0.031 \\
\hline Lumen volume & $169 \pm 110$ & $201 \pm 144$ & $233 \pm 174$ & 0.012 \\
\hline P\&M volume & $163 \pm 139$ & $201 \pm 155$ & $232 \pm 176$ & 0.013 \\
\hline
\end{tabular}

EEM: external elastic membrane, CSA: cross-sectional area, P\&M: plaque plus media, IVUS: intravascular ultrasound 
troponin I levels were highest in the highest tertile group.

\section{Angiographic findings}

Angiographic findings are summarized in Table 2. There were no significant differences in the culprit vessel, lesion location, the incidences of multivessel disease, Thrombolysis in Myocardial Infarction flow grade, and reference diameter between three groups. However, minimal lumen diameter was smallest in the highest tertile group.

\section{Grey-scale intravascular ultrasound results}

Grey-scale IVUS findings are summarized in Table 3. There were no significant differences in the IVUS parameters at the proximal and distal references. At the minimum lumen sites, P\&M CSAs were greatest and IVUS lesion length was longest in the highest tertile group. Plaque rupture and multiple plaque ruptures were observed most frequently in the highest tertile group ( $28 \%$ vs. $36 \%$ vs. $51 \%, \mathrm{p}<0.001$, and $15 \%$ vs. $22 \%$ vs. $30 \%, p=0.014$, respectively). By volumetric analysis, EEM, lumen, and P\&M volumes were greatest in the highest tertile group.

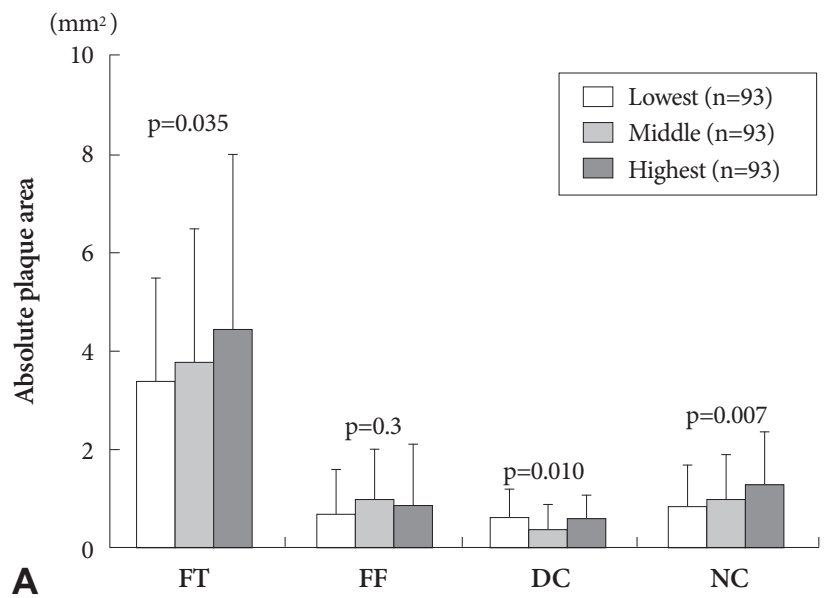

Virtual histology-intravascular ultrasound results

At the minimum lumen sites, absolute and $\% \mathrm{NC}$ areas were greatest in the highest tertile group (Fig. 2). By volumetric analysis, absolute and \%NC volumes were greatest in the highest tertile group (Fig. 3). The TCFA within culprit lesions was observed most frequently in the highest tertile group (Fig. 4).

\section{Independent predictors of high-sensitivity C-reactive} protein elevation and thin-cap fibroatheroma

Multivariate analysis was performed to identify independent predictors of hs-CRP elevation. Variables with $p<0.2$ in the univariate analysis (age, diabetes mellitus, ejection fraction, $\mathrm{N}$-terminal pro-B-type natriuretic peptide, white blood cell count, hemoglobin, serum glucose, troponin-I, LDL-C, P\&M volume, IVUS lesion length, volumetric VH-IVUS parameters: absolute FT, DC and NC volumes, relative FF, DC, and NC volumes) were evaluated for multivariate analysis. Diabetes mellitus \{odds ratio (OR): 2.73, 95\% confidence interval (CI): 1.20-5.42, $\mathrm{p}=0.009\}$, N-terminal pro-B-type natriuretic peptide (OR; 1.24, 95\% CI=1.12-1.36, $\mathrm{p}=0.008$ ) and absolute NC volume (OR; 1.03, 95\% CI=1.06-1.21, $\mathrm{p}=0.004)$ were in-

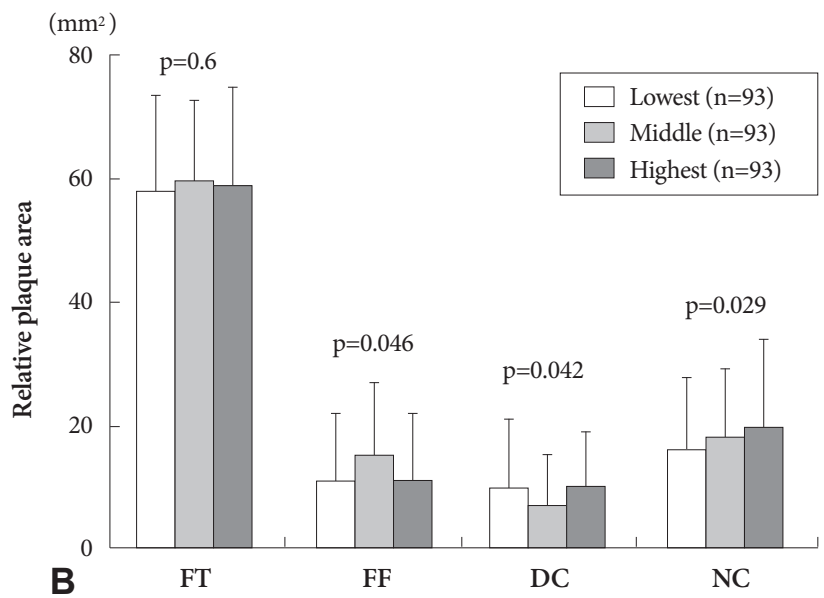

Fig. 2. The absolute and relative plaque components at the minimum lumen sites. FT: fibrotic, FF: fibro-fatty, DC: dense calcium, NC: necrotic core.
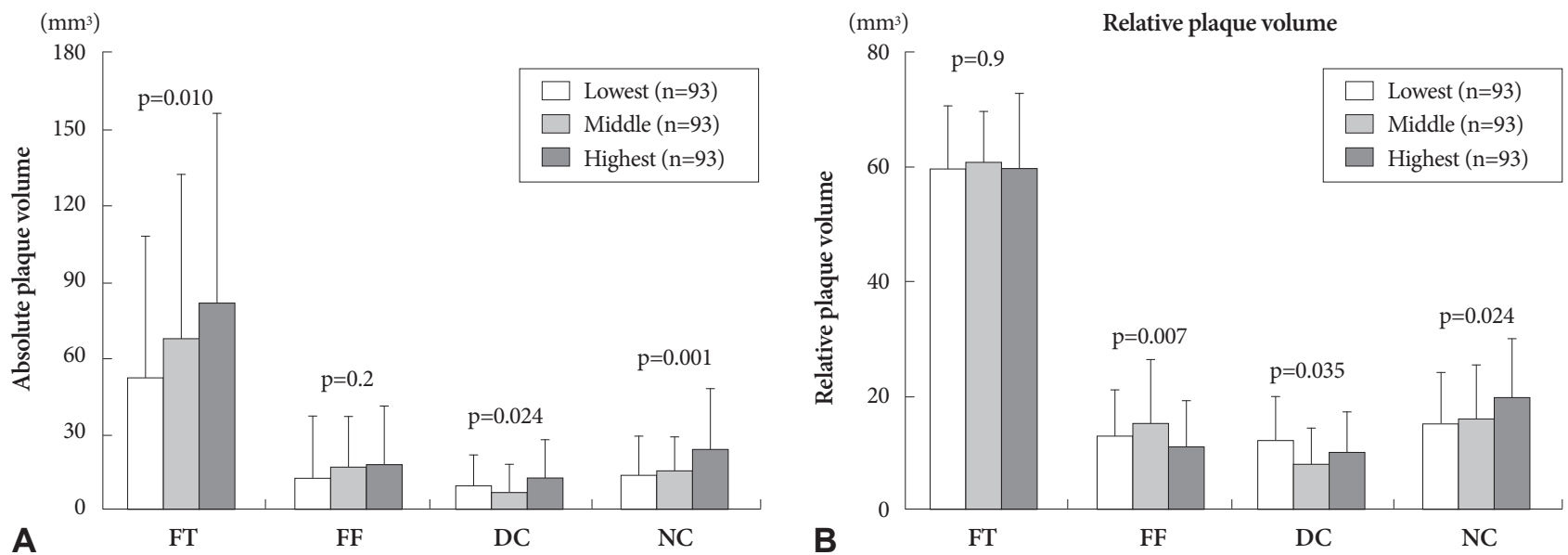

Fig. 3. The volumetric absolute and relative plaque components. FT: fibrotic, FF: fibro-fatty, DC: dense calcium, NC: necrotic core. 


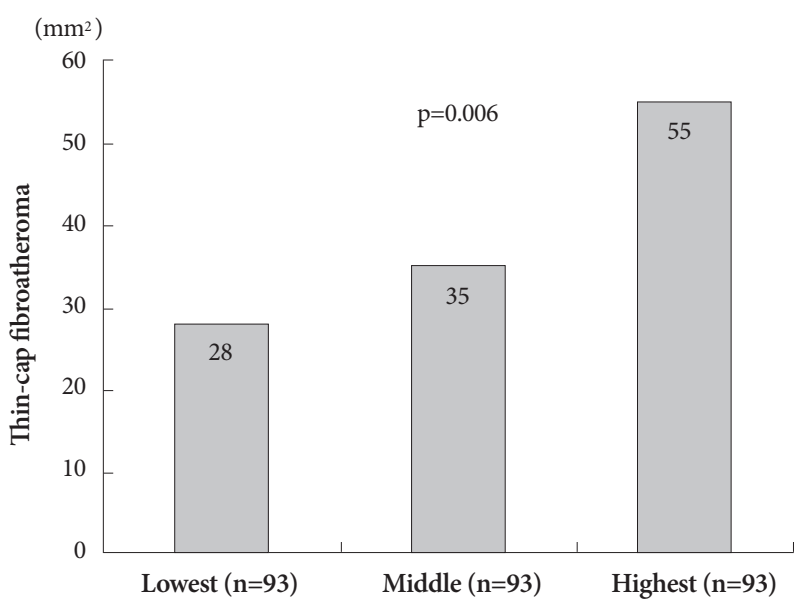

Fig. 4. The incidence of thin-cap fibroatheroma.

dependent predictors of hs-CRP elevation.

We performed multivariate analysis to determine independent predictors of culprit lesion TCFA. All variables with $\mathrm{p}<$ 0.2 in the univariate analysis (age, male gender, diabetes mellitus, hypertension, smoking, ejection fraction, hs-CRP, and P\&M volume) were evaluated for multivariate analysis. Diabetes mellitus (OR: 2.14, 95\% CI: 1.30-3.60, $\mathrm{p}=0.008$ ) and the hs-CRP (OR; 1.86, 95\% CI=1.11-2.90, $\mathrm{p}=0.010$ ) were independent predictors of TCFA.

\section{Discussion}

The present VH-IVUS study demonstrated that 1) the highest hs-CRP tertile group has the most diabetics, and had the greatest P\&M volume as well as absolute and \% $\mathrm{NC}$ volumes; 2) the culprit lesion TCFA was observed most frequently in the highest hs-CRP tertile group; 3) absolute NC volume was an independent predictor of hs-CRP elevation; and 4) the hs-CRP was an independent predictor of TCFA.

CRP has emerged as a simple tool for detecting systemic inflammation. ${ }^{4)}$ An elevated CRP level is associated with increased risk of future fatal or non-fatal ischemic complications in ACS patients. ${ }^{1617)} \mathrm{A}$ previous study demonstrated that CRP was strongly associated with atherosclerosis measured at various sites in the arterial tree. ${ }^{18)}$ Several mechanisms have been described through which CRP and other inflammatory mediators may be actively involved in atherogenesis. ${ }^{19)} \mathrm{CRP}$ is produced by smooth muscle cells of atherosclerotic lesions, ${ }^{20)}$ and locally produced CRP could directly participate in atherogenesis and the development of cardiovascular complications.

Pathological studies have demonstrated that plaque rupture and subsequent thrombosis is the most important mechanism leading to ACS. ${ }^{2122)}$ Several grey-scale IVUS studies have demonstrated the association between CRP and vulnerable plaque in ACS patients. ${ }^{67710)}$ Sano et al. ${ }^{6)}$ reported that patients with elevated CRP levels had more plaque ruptures, compared with those with a normal CRP, and that plaque rup- ture correlated with elevated CRP level in the setting of AMI. Hong et al.7) reported that elevated CRP level was an independent predictor of plaque rupture in AMI patients using a 3vessel IVUS. Tanaka et al ${ }^{10)}$ reported that AMI patients with culprit lesion plaque ruptures presented with higher CRP levels, as compared with AMI patients without plaque rupture. The number of plaque ruptures correlated with CRP levels one month from onset.

VH-IVUS has the potential to provide detailed qualitative and quantitative information, and it can help identify four specific plaque components. Plaque components may play a role in plaque disruption and thrombosis that lead to acute coronary events. ${ }^{2324)}$ Lesions with a large lipid core may present higher risk of disruption than sclerotic plaques. ${ }^{2526)}$ TCFA is the precursor of plaque rupture, which accounts for a majority of coronary thrombi and coronary death. ${ }^{23227 / 28)}$ Several VH-IVUS studies have reported that ACS patients had more NC-containing plaques, and more TCFAs compared with stable angina patients. ${ }^{1112)}$ Burke et al. ${ }^{29)}$ reported correlation between CRP and the number of TCFAs in patients who experienced sudden death associated with severe coronary artery disease. In the present study, the NC component was greatest, and TCFA within culprit lesions was observed most frequently in patients with the highest hs-CRP tertile, and there existed a correlation between hs-CRP levels vs. NC components and TCFA, and cardiac enzyme levels were significantly higher after stenting in patients with TCFA, compared with patients without TCFA $\{\Delta$ (poststenting-baseline value) CK-MB: $+10.1 \pm 22.0$ U/L vs. $-3.8 \pm 26.1 \mathrm{U} / \mathrm{L}, \mathrm{p}=0.012 ; \Delta$ cardiacspecific troponin I: $+8.3 \pm 15.5 \mathrm{ng} / \mathrm{mL}$ vs. $-0.9 \pm 11.4 \mathrm{ng} / \mathrm{mL}$, p= $0.021\}$. The present study suggests that hs-CRP is associated with the development of vulnerable plaque in ACS patients. The NC components contain foam cells with lipid deposition, inflammatory cells, intramural bleeding, and cholesterol crystals. As such, they may be associated with CRP elevation in ACS patients.

There are several limitations to be mentioned. First, the present study is a retrospective single-center study and is subject to limitations inherent in this type of clinical investigation. Second, IVUS and VH-IVUS were performed at the discretion of individual operators leading to potential selection bias. Third, we did not attempt to differentiate between atherosclerotic plaque and thrombus, because VH-IVUS could not determine the presence of thrombus. This may obscure the identification of TCFA.

Fourth, heavily calcified plaques may induce an artifact regarding the codification of plaques by VH-IVUS, resulting in increased NC content. Fifth, serial follow-up of serum hs-CRP level was not performed. Therefore, we did not demonstrate the impact of sequential change of hs-CRP levels on plaque components.

In conclusion, ACS patients with elevated hs-CRP have more 
vulnerable plaque components (NC-rich plaques and higher frequency of culprit lesion TCFA), compared with ACS patients with normal hs-CRP.

\section{Acknowledgments}

This study was supported by a grant (K00060-282) from the Fundamental R\&D Program for Core Technology of Materials funded by the Ministry of Knowledge Economy, Republic of Korea.

\section{REFERENCES}

1) Choi H, Cho DH, Shin HH, Park JB. Association of high sensitivity $C$-reactive protein with coronary heart disease prediction, but not with carotid atherosclerosis, in patients with hypertension. Circ J 2004; 68:297-303

2) Nakanishi N, Shiraishi T, Wada M. C-reactive protein concentration is more strongly related to metabolic syndrome in women than in men: the Minoh Study. Circ J 2005;69:386-91.

3) Ridker PM, Glynn RJ, Hennekens CH. C-reactive protein adds to the predictive value of total and HDL cholesterol in determining risk of first myocardial infarction. Circulation 1998;97:2007-11.

4) Morrow DA, Braunwald E. Future of biomarkers in acute coronary syndromes: moving toward a multimarker strategy. Circulation 2003; 108:250-2.

5) Pearson TA, Mensah GA, Alexander RW, et al. Markers of inflammation and cardiovascular disease: application to clinical and public health practice: a statement for healthcare professionals from the Centers for Disease Control and Prevention and the American Heart Association. Circulation 2003;107:499-511.

6) Sano T, Tanaka A, Namba M, et al. C-reactive protein and lesion morphology in patients with acute myocardial infarction. Circulation 2003; 108:282-5.

7) Hong MK, Mintz GS, Lee CW, et al. Comparison of coronary plaque rupture between stable angina and acute myocardial infarction: a three-vessel intravascular ultrasound study in 235 patients. Circulation 2004;110:928-33.

8) Hur SH. Lesion characteristics in patients with acute coronary syndrome: a comparison with lesion in patients with stable angina by intravascular ultrasound. Korean Circ J 2004;34:548-57.

9) Nian M, Lee P, Khaper N, Liu P. Inflammatory cytokines and postmyocardial infarction remodeling. Circ Res 2004;94:1543-53.

10) Tanaka A, Shimada K, Sano T, et al. Multiple plaque rupture and Creactive protein in acute myocardial infarction. $\mathrm{J} \mathrm{Am} \mathrm{Coll} \mathrm{Cardiol}$ 2005; 45:1594-9.

11) Rodriguez-Granillo GA, García-García HM, Mc Fadden EP, et al. In vivo intravascular ultrasound-derived thin-cap fibroatheroma detection using ultrasound radiofrequency data analysis. J Am Coll Cardiol 2005; 46:2038-42.

12) Bae JH, Kwon TG, Kim KH, Hyun DW, Kim KY, Kim DS. In-vivo coronary plaque composition in patients with acute coronary syndrome: a virtual histology intravascular ultrasound study. Korean Circ J 2007;37:437-42.
13) Roberts WL, Moulton L, Law TC, et al. Evaluation of nine automated high-sensitivity C-reactive protein methods: implications for clinical and epidemiological applications. Part 2. Clin Chem 2001;47:418-25.

14) Mintz GS, Nissen SE, Anderson WD, et al. American College of Cardiology Clinical Expert Consensus Document on Standards for Acquisition, Measurement and Reporting of Intravascular Ultrasound Studies (IVUS): a report of the American College of Cardiology Task Force on Clinical Expert Consensus Documents. J Am Coll Cardiol 2001;37: 1478-92.

15) Bae JH, Rihal CS, Lerman A. Tissue characterization of coronary plaques using intravascular ultrasound/virtual histology. Korean Circ J 2006;36:553-8.

16) Blake GJ, Ridker PM. C-reactive protein and other inflammatory risk markers in acute coronary syndromes. J Am Coll Cardiol 2003;41(4 Suppl S):37S-42S.

17) James SK, Armstrong P, Barnathan E, et al. Troponin and C-reactive protein have different relations to subsequent mortality and myocardial infarction after acute coronary syndrome: a GUSTO-IV substudy. J Am Coll Cardiol 2003;41:916-24.

18) van der Meer IM, de Maat MP, Bots ML, et al. Inflammatory mediators and cell adhesion molecules as indicators of severity of atherosclerosis: the Rotterdam Study. Arterioscler Thromb Vasc Biol 2002;22: 838-42.

19) Libby P, Ridker PM, Maseri A. Inflammation and atherosclerosis. Circulation 2002;105:1135-43

20) Jabs WJ, Theissing E, Nitschke M, et al. Local generation of C-reactive protein in diseased coronary artery venous bypass grafts and normal vascular tissue. Circulation 2003;108:1428-31.

21) Davies MJ, Thomas A. Thrombosis and acute coronary-artery lesions in sudden cardiac ischemic death. N Engl J Med 1984;310:1137-40.

22) Farb A, Burke AP, Tang AL, et al. Coronary plaque erosion without rupture into a lipid core: a frequent cause of coronary thrombosis in sudden coronary death. Circulation 1996;93:1354-63.

23) Virmani R, Kolodgie FD, Burke AP, Farb A, Schwartz SM. Lessons from sudden coronary death: a comprehensive morphological classification scheme for atherosclerotic lesions. Arterioscler Thromb Vasc Biol 2000;20:1262-75.

24) Falk E, Shah PK, Fuster V. Coronary plaque disruption. Circulation 1995;92:657-71.

25) Davies MJ, Richardson PD, Woolf N, Katz DR, Mann J. Risk of thrombosis in human atherosclerotic plaques: role of extracellular lipid, macrophage, and smooth muscle cell content. Br Heart J 1993;69:377-81.

26) Buja LM, Willerson JT. Role of inflammation in coronary plaque disruption. Circulation 1994;89:503-5.

27) Virmani R, Burke AP, Kolodgie FD, Farb A. Pathology of the thin-cap fibroatheroma: a type of vulnerable plaque. J Interv Cardiol 2003; 16 : 267-72.

28) Virmani R, Burke AP, Farb A, Kolodgie FD. Pathology of the vulnerable plaque. J Am Coll Cardiol 2006;47(8 Suppl):C13-8.

29) Burke AP, Tracy RP, Kolodgie F, et al. Elevated C-reactive protein values and atherosclerosis in sudden coronary death: association with different pathologies. Circulation 2002;105:2019-23. 